\title{
Biodança como processo de renovação existencial do idoso
}

\author{
Biodance as process of existential renew for the elderly
}

Biodanza cómo proceso de renovación existencial para los ancianos

\author{
Bárbara Pereira D’Alencar', Maria Manuela Rino Mendes", \\ Maria Salete Bessa Jorge', José Maria Ximenes Guimarães ${ }^{1}$ \\ 'Universiade Estadual do Ceará. Departamento de Enfermagem. Fortaleza, CE \\ "Universidade de São Paulo. Escola de Enfermagem de Ribeirão Preto. Ribeirão Preto, SP
}

Submissão: 13/02/2007

Aprovação: 18/09/2008

\section{RESUMO}

Neste estudo, buscamos, a partir do método etnográfico, identificar os efeitos da Biodança nos idosos Que a vivenciam. O estudo foi realizado com oito idosos Que integram o grupo de Biodança do SESC de Fortaleza, Ceará. Os dados coletados por meio da entrevista semi-estruturada e da observação participante foram analisados pelo método de análise de narrativa. Na busca do significado da Biodança para os idosos, evidenciou-se Que ela constitui um mecanismo de enfrentamento das dificuldades com a saúde, estimulando a mudança de comportamento em relação às condições de saúde, por aumentar o ímpeto vital e a vontade de viver. Neste sentido, a Biodança promove o resgate da saúde de pessoas Que envelhecem.

Descritores: Etnografia; Saúde do idoso/enfermagem; Qualidade de vida.

\section{ABSTRACT}

In this study, we searched, from the ethnographic method, to identify the effects of Biodance in elders that lived it. The study was done with eight elderly that integrate the group of Biodance of SESC from Fortaleza, Ceará. The data were collected through semi-structured interview and participant observation, analyzed by method of narrative analysis. In the search of meaning of Biodance to elders, it highlighted that it constitutes a mechanism of facing of difficulties with health, stimulating the change of behavior in relation to health conditions, due increase the vital impetus and will to live. In this sense, the Biodance promotes the rescue of health that grew older.

Descriptors: Anthropology, cultural; dance therapy; Health of the elderly/nursing; Quality of life

\section{RESUMEN}

En este estudio se busca, a partir del método etnográfico, identificar los efectos de la biodanza en los adultos mayores Que la experimentan. El estudio fué realizado con 8 adultos mayores que integran el grupo de biodanza de la SESC de la ciudad de Fortaleza, Ceará, Brasil. Los datos recolectados a traves de la entrevista semiestructurada y de la observación participante, fueron analizados por el método del análisis narrativo. En la busqueda del segnificado de la biodanza para las personas mayores de edad, se evidenció Que ella constituye un mecanismo de enfrentamiento hacia las dificultades en su salud, estimulandolos a los cambios de comportamiento en relación a las condiciones de salud, aumentar su impetu vital y la voluntad de vivir. En este sentido, la biodanza promueve el rescate de la salud de las personas Que envejecen.

Descriptores: Antropología cultural; Salud del anciano/enfermería; Calidad de vida. 


\section{INTRODUÇÃO}

As projeções demográficas apontam para considerável aumento da população idosa em todo o mundo. Consoante estimativa, no ano de 2025 o Brasil terá $15 \%$ da população composta por pessoas acima de 60 anos. Concorrem para tal fato as políticas de planejamento familiar adotadas, a partir das Quais houve redução do numero de crianças menores de 14 anos e a adoção de medidas de controle de doenças infecto-contagiosas tem resultado no significativo aumento da população na faixa etária de 15 a 59 anos e acentuada elevação do número de pessoas acima de 60 anos $^{(1)}$. Paralelamente, observa-se a transição epidemiológica, expressa pelo aumento crescente de doenças crônico-degenerativas nessa faixa etária, aumentando também a necessidade de serviços de atenção à saúde dos idosos.

Por outro lado, na velhice as pessoas geralmente têm seu tempo disponível ampliado pela aposentadoria, crescimento e independência dos filhos. Situações estas Que, em geral, as levam ao sentimento de inutilidade e solidão, motivos de intenso sofrimento.

A abordagem do valor clínico das relações afetivas a partir do apoio dos amigos inclui a solidão na lista de riscos emocionais para a saúde e os laços emocionais estreitos no rol de fatores protetores $^{(2)}$. O isolamento social é tão importante para as taxa de mortalidade Quanto o fumo, a hipertensão, o colesterol elevado, a obesidade e a falta de exercícios físicos e a sensação de não ter com Quem contar consiste em risco para a saúde, destacando-se o estilo de vida nas modernas sociedades urbanas e o crescente isolamento gerado pelo hábito de, sozinho, ficar a ver televisão.

A morte social a que o idoso é submetido faz com Que ele assuma uma postura confundida, pela sociedade, com doença, na busca de se proteger das agressões ambientais. A imagem Que se configura a partir disso é Que este não terá mais capacidade física para desempenhar suas atividades, uma vez Que seu corpo já não tem tanta vitalidade como outrora e, então, adota postura de passividade e dependência, gerada, Quase sempre, pela falta de estímulos. Aos poucos vai se isolando, reduzindo sua motricidade, buscando menos os contatos sociais, rompendo, então, com seus vínculos afetivos, transformando-se naQuela pessoa solitária, poliqueixosa e, conseqüentemente, no velho que a sociedade rejeita.

A partir dessa constatação, faz-se necessária a busca de recursos possíveis de facilitar o enfrentamento das dificuldades vivenciadas pelos idosos, como a solidão, a falta de alegria de viver, entre outras, traduzidas como vazio existencial e, deste modo, resgatar a vontade de viver, a alegria de estar com os outros e a percepção de suas potencialidades.

A família precisa ser sensibilizada, possibilitando as interações sociais para o idoso, tanto dentro Quanto fora dela, pois, no dizer de Goleman ${ }^{(2)}$, os relacionamentos mais importantes e as pessoas com Quem mantemos contato no cotidiano são fundamentais para nossa saúde.

$\mathrm{Na}$ busca de alternativas para o enfrentamento desses problemas, a Biodança tem sido o método mais indicado em geriatria, visto Que a reabilitação do idoso deverá ser pensada como princípio unitário no Qual se incluem níveis orgânicos, motores, afetivos, intelectuais e sociais ${ }^{(3)}$. A percepção de tantos problemas vivenciados pelos idosos na sociedade moderna reQuer a adoção do Principio
Biocêntrico, base da Biodança, com a proposta de "criar mais vida dentro da vida", para construir a grande roda da solidariedade.

Os exercícios de Biodança com idosos são orientados no sentido de equilibrar funções psicológica ${ }^{(3)}$. Apresenta, ainda, como vantagens o desenvolvimento dos potenciais dos idosos por meio do método, o que permitiria uma Qualidade de vida bem mais satisfatória, pois, com certeza, a pessoa estaria mais integrada consigo mesma, mais harmonizada com as outras pessoas e com a natureza e, conseqüentemente, com um menor número de $\operatorname{conflitos}^{(4)}$.

Os efeitos benéficos da Biodança para a saúde das pessoas têm chamado atenção de vários profissionais da área. Constituem prática possível de atenuar patologias, como transtornos mentais; diabetes e hipertensão arterial, Que atingem a maioria da população idosa ${ }^{(5-8)}$.

Diante deste contexto, delimitamos como tema básico para este estudo a utilização da Biodança como um recurso para a promoção da saúde dos idosos, estimulada mediante relacionamentos nutridores, num processo de viver baseado na solidariedade e seus significados, Que são elaborados pelas pessoas Que participam de um grupo comunitário; significados estes Que podem ser diversificados, tendo em vista as experiências pessoais e culturais.

Na procura de respostas para indagações sobre a representação dessa atividade em suas vidas e Qual a contribuição Que a enfermagem, como cuidado solidário ${ }^{(9,10)}$ poderia dar, rumo ao envelhecer saudável, elegemos como Questão norteadora do estudo: como a Biodança tem influenciado a saúde dos idosos que a praticam? Neste sentido, nosso objetivo foi identificar os efeitos da Biodança na saúde dos idosos Que a vivenciam no grupo existente no SESC em Fortaleza.

\section{METODOLOGIA}

No presente estudo, optamos pela epistemologia Qualitativa, para a realização do estudo de caso, com abordagem etnográfica. A pesquisa etnográfica possibilita a descrição de eventos Que ocorrem na vida de um grupo; os comportamentos dos indivíduos em relação a sua participação no grupo e a sua interpretação dos significados desses comportamentos para o grupo.

A pesquisa realizou-se na cidade de Fortaleza, Ceará, região Nordeste do Brasil, especificamente no Serviço Social do Comércio (SESC), uma instituição particular, com personalidade jurídica de direito privado, criada e mantida pelos empresários do comércio e empregados, Que desenvolve vários trabalhos com pessoas acima de 50 anos, a exemplo da Biodança, Que desde o início dos anos 90 passou a fazer parte das atividades de promoção da Qualidade de vida dos idosos. Não tem fim lucrativo, sendo os recursos aplicados na assistência ao trabalhador comerciário.

Os sujeitos do estudo foram oito pessoas idosas eleitas entre as Quinze Que participavam do grupo de Biodança do SESC, Regional de Fortaleza-Ce, no período de fevereiro de 2003 a outubro de 2004, Que aceitaram contribuir com esta pesquisa.

Os dados da pesquisa foram obtidos por meio de entrevistas semi-estruturadas e de observação participante do grupo, Que se reunia uma vez por semana no SESC. A modalidade de participação no trabalho na condição de "observação como participante", considera que a identidade do pesquisador e os objetivos do estudo são revelados ao grupo pesQuisado desde o início( ${ }^{(1)}$. 
A análise dos dados das narrativas dos idosos participantes do grupo de Biodança pautou-se pela busca de coerência entre o pensamento de Paul Ricoeur, com influência na concepção de Geertz ao interpretar as culturas ${ }^{(12)}$. Assim, a explicação foi em direção à análise das relações internas do texto, Que compõe as partes do discurso e tenta compreender os significados Que o discurso revela, ou seja, o todo em relação às partes.

Propõem-se cinco temas Que constituem os passos metodológicos para objetivação do texto, a Qual possibilita o distanciamento e apropriação, Que juntamente com a explicação e a compreensão vão permear a interpretação: a efetuação da linguagem como discurso; a efetuação do discurso como obra estruturada; a relação da fala com a escrita no discurso e nas obras do discurso; a obra do discurso como projeção de um mundo; o discurso e a obra de discurso como mediadores da compreensão de si ${ }^{(13)}$.

De acordo com este método, interpretar é um processo Que compreende os seguintes passos metodológicos: fixação das entrevistas num texto, leitura simples do material, análise estrutural e compreensão abrangente ou profunda.

Por se tratar de pesquisa no âmbito do processo grupal envolvendo as falas, opiniões e ações das pessoas Que participam de um grupo, buscamos dar atenção especial aos aspectos éticos envolvidos na pesquisa. Implica dizer Que foi submetida à aprovação do Comitê de Ética em Pesquisa da Universidade Estadual do Ceará, obtendo parecer favorável. Além disso, encaminhou-se ofício à direção do SESC e à facilitadora do grupo, solicitando a permissão para desenvolver o trabalho naquela instituição, no Qual se assegurava o respeito aos princípios éticos da pesQuisa abrangendo seres humanos.

Cada participante foi convidado para expressar sua permissão em participar do estudo com assinatura do termo de consentimento livre e esclarecido.

Ressaltamos Que na perspectiva de assegurar o anonimato dos sujeitos, os nomes citados nas narrativas são fictícios, os Quais representam nomes de flores, escolhidos pelos sujeitos.

\section{RESULTADOS E DISCUSSÃO}

\section{Autopercepção de Saúde-Doença: a Biodança como Caminho para a Cura}

Em se tratando de saúde-doença, podemos observar o processo cultural acontecendo, num compartilhar de ações e idéias acerca de como se adoece e como ocorre a cura e o enfrentamento do adoecer. Se por um lado temos o modelo biomédico estabelecido como "dono do saber", Que sofreu a influência do saber compartimentalizado do corpo e da alma, dissociado também da cultura, por outro lado, temos o modelo cultural de saúde, passado de geração a geração, em Que se utilizam os próprios recursos da comunidade. Assim, estudiosos buscam explicar o processo saúdedoença pela ótica cultural e interpretativa das culturas, respectivamente ${ }^{(14,15)}$.

A cultura é uma teia de símbolos e significados que permite ao indivíduo, famílias e aos grupos interpretarem as suas experiências e guiarem suas ações ${ }^{(15)}$. Neste sentido, delimitamos os adoecimentos dos elementos do grupo e as formas como enfrentaram o adoecer.

Por ser um processo dinâmico, o estado de saúde oscila em determinados momentos das vidas Que marcaram a vida atual; assim como adoecimentos Que estão presentes no cotidiano dos idosos, Quando da época da pesquisa.

Vejamos o Que ocorreu com Rosa Amélia, antes de se tornar participante do grupo:

da saúde... eu tirei um câncer de mama, a esquerda, já faz três anos agora em janeiro... levei todos os exames e o médico disse: vamos fazer o Quadrante. Aí eu disse: doutor, pois não faça $o$ Quadrante, tire logo tudo mesmo, porQue senão daQui a dois ou três anos é preciso fazer novamente e é melhor "cortar o mal pela raiz"...aí ele fez. [...I nunca derramei uma lágrima. Aí minhas vizinhas choravam...a Dona M...e a Dona L... mas eu nunca chorei não.

$\mathrm{Na}$ narrativa de Rosa Amélia, podemos perceber a sua participação no tratamento do câncer, Quando teve a oportunidade de decidir o método operatório com seu médico, após conversação e entendimento. Isso faz com Que a paciente sinta-se parte ativa no seu tratamento. É importante considerar Que a conversação integra esse tratamento e domina a dimensão decisiva de toda ação médica, humaniza a relação entre os indivíduos, Que são fundamentalmente distintos, o médico e o paciente ${ }^{(16)}$.

Observamos também o compartilhamento da doença na rede social, Quando ela afirma Que sua vizinhança chorou por ela, ao primeiro impacto da notícia do câncer de mama, doença Que é culturalmente conhecida como mortal.

A pressão alterou... aí eu fieuei tomando remédio. Eu toda vida tive dificuldade de respirar...PorQue a gente enche o peito de ar, é muito bom. Esse negócio de depressão, Quando a gente ta ali, naquela roda, aqueles movimentos, ninguém se lembra de problema. (Rosa Amélia)

A cultura é um tecido social de símbolos e significados, Que permite às pessoas, famílias e aos grupos sociais, interpretarem os eventos Que ocorrem em suas vidas e guiarem as formas de responder a esses eventos. QualQuer desordem, física ou psicológica pode ser alcançada por meio da mediação cultural ${ }^{(14,15,17,18)}$. Todas as atividades de cuidados em saúde são respostas socialmente organizadas em frente das doenças e podem ser estudadas e compreendidas como sistema cultural.

No cotidiano da mulher com câncer de mama estão presentes fatores de esperança, de fé e de agressividade, sendo Que "Quem mostra uma dessas características consegue mais facilmente orientar-se para o futuro e/ou expressar e aliviar suas tensões internas, o Que pode prolongar consideravelmente a sobrevivência ou mesmo produzir remissões espontâneas"(19).

Apesar de Rosa Amélia nunca ter mencionado no grupo de Biodança sua história de ter tido câncer de mama, acreditamos Que o suporte afetivo dado pelo grupo pode contribuir para o enfrentamento da doença, pois, "naquela roda ninguém se lembra de problemas... a Biodança ajuda a esquecer", como disse.

O suporte social pode ser visto como fenômeno interpessoal, Que é conduzido pela expressão do cuidar, reafirmação de confiança e validação do valor pessoal ${ }^{(8)}$.

Este suporte pode ser compreendido como forma de 
solidariedade - elemento que está radicado na essência social do ser humano, correspondendo a um dos deveres mais fundamentais da vida social ${ }^{(10)}$.

Neste sentido, Girassol, Que tinha estrabismo, passou toda sua vida sendo discriminado e somente agora criou coragem para se operar. Isso porque teve apoio da rede social, Quando em conversas com parentes descobriu Que poderia corrigir seu problema e realizar seu sonho, como segue no relato:

Esse problema na minha vista [estrabismo], a minha mãe legítima dizia que foi de uma Queda, não foi, foi de nascença... Eu tinha muita vontade de operar e não tinha condições. [...] eu me tratava com um oculista há Quase 20 anos, fui falar com ele... ele foi e disse que eu não tinha condições porQue eu não ia enxergar mais... era só uma Questão de estética... de beleza. [...] Aí, conversando com uma cunhada minha ela disse: Vá na minha neta,..Eu fui a ela...Quando cheguei lá falei com ela. Ela disse: não, seu G... Não vai perder nada do seu outro olho bom... Não vai. Isso é a coisa mais simples. Meu pai era assim e eu operei. ... Aí peguei e fiz.

Vale ressaltar o poder médico, Quando prevê que Girassol poderia prejudicar a vista boa e, assim, ficar condenado a conviver com um problema "de estética" como o estrabismo, tirando a oportunidade de realizar um sonho, o de melhorar sua auto-imagem e, conseQüentemente, sua auto-estima. Foi uma realização, um presente que Girassol deu a si mesmo.

As maneiras como os modelos explicativos leigos e os médicos interagem na consulta médica são influenciadas não só pelo contexto físico em Que ocorrem mas também pela classe social e o gênero das duas partes envolvidas ${ }^{(20)}$. Após a cirurgia, Girassol recebeu visita das colegas de grupo e demonstrava muita alegria Quando Ihe diziam que ficara mais bonito; isso era muito importante para ele, especialmente por relatar Que foi discriminado, na infância, por seu pai adotivo, "por ser feio". Isso só foi possível por meio da interação e da solidariedade na rede social.

Em carta de amor para si mesmo, feita durante uma maratona de Biodança, Girassol escreveu, após olhar-se num espelho:

“eu ... me amo muito por ter meu corpo perfeito, com todos os meus membros. Procuro zelar por ele, Que foi Deus que me deu... Eu me amo".

Como se percebe, na fala de Girassol, ele sente-se saudável porQue ainda consegue dançar a noite toda. Neste sentido, a saúde é percebida pelo vigor e atividade física.

O processo pelo Qual a doença, numa perspectiva do paciente "illness" é padronizada, interpretada e tratada, é chamado por Kleinman de modelo explicativo, Que é definido como o conjunto de idéias de todos os envolvidos no processo clínico sobre um episódio de doença e seu tratamento para orientar as escolhas entre as terapias e os terapeutas disponíveis, assim como para elaborar os significados pessoal e social da experiência de doença ${ }^{(14)}$.

Outra narrativa Que nos leva a crer na melhora da saúde através da Biodança, é dada por Acácia:

... Eu sentia dor nos meus ossos, em tudo Quanto era osso. QualQuer coisinha era... vivia na fisioterapia, direto. Na coluna todinha eu tinha bico de papagaio, está lá constatado... realmente eu tenho uma hérnia na lombar, Que eu operei, uma hérnia cervical que eu ainda tenho, tenho artrose, tenho lordose aqui embaixo...lá se vai eu pra fisioterapia. Quando não era nas costas, era pros Quartos... . Eu não precisei mais de fisioterapeuta e ta caminhando pra um ano agora, Que eu não sei o que é dor na coluna. Tô jóia, linda e maravilhosa.

A renovação orgânica é induzida principalmente mediante estados especiais de transe Que ativam processos de renovação e regulação global das funções biológicas, diminuindo os fatores de desorganização (entropia do sistema). E, por um processo, o sentimento de "melhora" vai surgindo lentamente, sendo percebido gradualmente ${ }^{(3)}$.

A saúde de Acácia se revela também em sua postura de alegria e participação nos eventos sociais:

Depois que eu saio, ótimo. Mas até eu sair...Tem dia que eu não tô afim, eu não Quero sair..eu não vou sair, sabe?Antes da Biodança, "problema de idade", "tá ficando velha", o que diziam lá em casa, aí eu fui me acomodando...eu não saia mais de casa, só saia pra igreja, ia pro colégio por obrigação e olhe lá...Eu acho Que Quando a gente vai envelhecendo...tem Que procurar...se tá aparecendo problema, tem que procurar melhorar. A vitalidade melhorou $1000 \%$, ave Maria! Você precisa me ver no Náutico (clube) dancei a noite toda, linda e maravilhosa! Com toda vitalidade, com toda criatividade... com toda energia...".

Quando sentiu Que estava adoecendo, Acácia procurou recurso profissional. Assim, buscou a Biodança como ajuda terapêutica, a partir do encaminhamento de sua psicóloga.

Apesar do apoio recebido, é importante Que no ambiente familiar o idoso seja estimulado e valorizado, pois comentários depreciativos, como os citados por Acácia, vão levando à baixa auto-estima, Que por sua vez leva ao isolamento social. Assim, passam a acreditar Que "já estão passadas", como Acácia diz, o Que em outras palavras significa Que já não tem mais valor, não tem mais direitos. Isso tem sido motivo de conflitos em seu ambiente familiar, especialmente em relação ao marido, Que parece se incomodar com toda a vitalidade de Acácia, o Que é percebido em seu discurso ao falar de seu comportamento numa festa no Clube Náutico, Quando estava demonstrando muita alegria e vitalidade.

Diante dos benefícios percebidos na saúde, a partir da Biodança, os idosos recomendam-na como terapia, como meio para a recuperação da saúde.

[...] porque todos aQueles movimentos servem... AQuelas danças... a gente deita e levanta, a pessoa não fica enrijecida. [...]então, se não vai ficar boa, pelo menos melhora... Quem tem bursite, tem artrose, sentia a coluna... com vários meses de Biodança a pessoa nem falava mais do problema do joelho, da coluna, do ombro... E o principal é que serve pra cabeça das pessoas. (Flor de Lótus)

\section{Processo Permanente de Renovação Existencial}

Em Biodança o sentido de renovação existencial tem o mesmo sentido da autopoiese, visto Que as transformações ocorrem tanto 
em nível biológico, Quando observamos a melhora na Qualidade da saúde, Quanto no plano mental, ao percebemos que as pessoas se revelam mais integradas consigo mesmas, mais harmonizadas e felizes e, no plano social, Quando as pessoas buscam melhor integração com os outros e com todo o ambiente a sua volta. Emprega-se a palavra autopoiese para definir o ser humano como sistema Que se produz continuamente e, para isso, faz-se necessária a interação com o meio ambiente, ambos se modificando de forma congruente ${ }^{(21)}$.

Comparando-se os sistemas vivos com o sistema social, ressaltamos Que os sistemas vivos, para dar continuidade ao processo de renovação, descartam suas células mortas. Conforme Mariotti, a sociedade, por ser um sistema vivo, não pode prescindir dos seus velhos, pois estes ainda têm vida e enQuanto estiver viva, nenhuma unidade autopoiética descarta Quaisquer dos seus componentes vivos. E se assim o faz, essa sociedade é automutiladora e, portanto, patológica ${ }^{(22)}$.

Trabalhar com a Biodança e os idosos é descobri-los renascidos, como se observou nas unidades de significados desveladas na análise de suas narrativas, em que brotam a liberdade, a autonomia e o vínculo com a espécie humana.

A Biodança eu achei fundamental na minha vida, me mudou totalmente. Primeiro, eu fieuei desinibida. Foi o amor que eu passei a sentir pelas pessoas. Eu tinha um defeito de... a gente não se abraçava, não se beijava... e eu passei a abraçar e beijar as pessoas. A gente vai sentindo as emoções e os nossos problemas são tão parecidos com as outras pessoas e isso é um consolo (Flor de Lótus).

Quando Flor de Lótus fala da dificuldade de tocar o outro, parece ser porta-voz de toda uma geração, habituada a não tocar e não expressar a alegria de estar com o outro. Neste aspecto, ressaltase a importância do tato como sentido fundamental para a vida humana, a estimulação tátil é muito importante, porém a mais negligenciada das necessidades. Contudo, é preciso observar as respostas dos idosos a um carinho, a um abraço, a um aperto de mão, a um apertão afetuoso, para sentir o Quão vitalmente necessárias são essas experiências para o seu bem-estar ${ }^{(23)}$.

Essa estimulação tátil, de Que fala o autor, pode se manifestar em forma de "aconchego", como se percebe nas palavras de Saudade:

... a parte que eu mais gosto é da roda, do colo, daquelas danças, eu acho interessante e gosto muito. Eu sinto aquele carinho, aquele aconchego. Antigamente eu não tinha esse aconchego, nem na minha casa. Era falta de costume abraçar.

Ao despertar sentimentos adormecidos no idoso e tornar mais rica de emoção sua vida, a Biodança o liberta da miséria de amor a ele imposta, permite vivenciar a si próprio como ser uno e integrado. $\mathrm{E}$, ao se vincular consigo e com os outros, o idoso pode fazer escolhas adequadas e adeuire novas posturas diante da vida ${ }^{(6)}$.

Ao nos depararmos com a afirmação "ninguém cresce sozinho" de Flor de Lótus, lembramos Que a identidade é permeável à presença do outro, ou seja, o outro é ponte para o nosso crescimento; as situações de encontro, com determinados movimentos permeados pela música, induzem vivências possíveis de modificar o organismo e a existência humana em diferentes níveis: orgânicos, estilo de vida, e até mesmo os processos socioculturais ${ }^{(24)}$.

Isso pode se confirmar também nas palavras de Margarida, ao afirmar:

"eu me modifieuei muito... me desenvolvi tanto.. tanto fisicamente ... como mentalmente, porQue minha mente tem se modificado muito... Eu hoje sou outra pessoa".

A mudança na forma de se comportar no ambiente social também foi experienciada por Rosa Amélia, ao reconhecer Que:

"antes da Biodança eu acho Que toda vida me relacionei bem com as pessoas... mas depois da Biodança melhorou mais ... Porque depois da Biodança a gente tem mais facilidade de se expressar..."

O sentimento de estar vivo por meio do outro e com o outro, mediante a exaltação das próprias características, é capaz de reforçar todos os circuitos de identidade saudável como também a vitalidade do individuo ${ }^{(24)}$. Esta perspectiva é expressa por Margarida, ao assegurar:

Agora eu acho Que tô vivendo melhor a vida... Abri mais as perspectivas prá mim. Antes eu achava que estava só doente... Eu até tinha medo de sair, porque eu achava que ia me sentir mal por ai... AdQuiri energias... tanta coisa aprendi lá, nessa Biodança. Hoje já converso mais, graças a Deus! Faço parte do círculo bíblico, faço parte do grupo de oração,... Vou até entrar para o bloco de carnaval.

Considera-se Que a inserção nos grupos é benéfica porQue proporciona um ambiente de convivência social e integração e são realizadas inúmeras atividades tais como trabalhos manuais, exercícios físicos, dança, teatro, coral, troca de receitas alimentares e fazer viagens em grupo torna a vida mais movimentada e alegre ${ }^{(25)}$.

Margarida, ao afirmar Que:

"hoje já penso de outra maneira... a Biodança contribuiu para essa transformação... eu era muito travada. Na Biodança eu aprendi que eu tenho Que procurar viver... aprender mais alguma coisa",

Revela o Quanto foi beneficiada com a Biodança e nos dá a dimensão da sua renovação existencial. Enfim, esta atividade pode ser meio no Qual se experiencie um significado existencial, visto Que pode oferecer a obtenção de satisfação pessoal para o idoso, por despertar significado à existência e a vivencia de situações das Quais provem sentido à vida.

A mudança de postura perante a vida também é perceptível na narrativa de Acácia, Quando diz:

É muito interessante... eu era uma pessoa muito receosa ... Eu passei a vida toda, todo mundo me mandando; faça isso, faça aquilo... Eu não gosto de ser mandada... Eu peguei e espontaneamente falei... Que ela tava Querendo ouvir, né? Em 
tempos atrás eu jamais colocaria, falaria... eu ficaria em cima do muro. .. Eu acho Que isso ai foi um grande passo, um dos caminhos que a Biodança me levou.

Acácia está se reportando a um momento da intimidade verbal do grupo, em eue uma pessoa falava de um conflito seu e pedia a opinião dos companheiros. $\mathrm{O}$ fato de ter dado conselho soou para ela como um grande passo em seu crescimento pessoal. Neste contexto, é importante frisar Que é nos momentos mais inesperados Que o participante de Biodança se percebe modificado, pois passa a agir de forma diferente.

Deste modo, libertar as pessoas das atitudes repetitivas, estimuladas por uma educação castradora, por meio da criatividade faculta-lhes tomar consciência de sua realidade, aumentar a confiança em si mesma, os interesses artísticos e criativos. Admitese Que criar equivale, entre outras coisas, a transformar, a inovar, a mudar a si mesmo e ao mundo, com o mesmo gesto ${ }^{(26)}$.

Os exercícios da linha da criatividade são inspirados em danças tribais. Neles a dança é usada como expressão; os desenhos são interpretados apenas pelo individuo na sua postura existencial. As mudanças são sutilmente percebidas pela pessoa na sua vida diária. Por outro lado, o trabalho com a linha da afetividade desenvolve a cooperação e integração intra-espécie, ao estimular o instinto gregário.

\section{CONSIDERAÇÕES FINAIS}

Ao se adotar um método como a Biodança, Que busca compreender o ser humano na sua dimensão holística e procura restaurar, mediante vínculo afetivo pessoal e com outros, a integração do ser, cuja base conceitual, provém da meditação sobre a vida, ou talvez do desespero, do anseio de renascer dos nossos gestos, da nossa vazia e estéril estrutura de repressão, os potenciais de felicidade tendem a alcançar estados cada vez mais intensos de satisfação com a vida.

Os seres humanos são capazes de compreender o seu sofrimento Quando sua identidade é "Quebrada". Mas, ao partir do principio de Que o ser humano tem a potencialidade da autopoiese, recomenda-se Que não seja examinada a miséria, mas, sim, uma conspiração pelos atos de viver, pelo desabrochar suave das potencialidades humanas, o Que só é possível num contexto sensível e criativo do encontro humano - o grupo. Desse modo, ao integrarem o grupo de Biodança, muitos idosos têm Queixas, principalmente de doenças. Mas gradativamente, seus discursos vão mudando, à medida Que são estimulados seus potenciais.

Os progressos físicos num grupo de idosos podem parecer mínimos e demorados, mas já é uma vitória tirá-los de casa e lhes mostrar como é gratificante descobrir o Quanto é bom estar com os outros e aconchegar-se no ninho ecológico, como perceberam Margarida e Rosa Amélia; sentindo-se fazer parte da espécie humana, podendo se expressar; experimentando tocar e ser tocadas, mesmo Que, no início, um toque apenas com as pontinhas dos dedos, como faziam Girassol e tantos outros. Afinal, o corpo do outro sempre lhes pareceu um campo minado... E agora podem usar sua pele, não mais como um órgão de defesa ou de separação do outro, mas como elemento de união entre as pessoas. Agora podem abrir os olhos e descobrir no olhar do outro que é possível o encontro humano. Podem iniciar a caminhada pela vida, não importando em Que idade; no início, com passos vacilantes, mas descobrindo Que podem caminhar com determinação e ir a busca do seu projeto existencial, como constatou Acácia.

Descobrem Que ainda é tempo de sonhar com o amor, como ocorreu com Papoula e Girassol, pois a vida pulsa nessa semente Que aos poucos vai desabrochando. E assim como o maestro rege a orquestra, é possível reger a própria vida, libertando-se da superproteção e dos cuidados com Que os velhos são tratados, e tocar sua própria sinfonia, fazendo de sua vida uma linda música.

Observamos Que houve aumento do ímpeto vital e da vontade de viver. Houve também diminuição da insegurança, o Que se revela Quando os idosos passaram a se expressar melhor, demonstrando alegria de viver e mais participação em eventos sociais.

No tocante à saúde, apesar de os discursos enfatizarem mais os adoecimentos, a saúde se revelou pelo aumento da capacidade física para fazer coisas, da redução de Queixas e do sentimento de ainda ser "forte". Pudemos constatar a grande influência da rede social nas questões relativas ao tratamento de doenças, entendendo o Quanto é significativa a mediação cultural durante os adoecimentos, o Que mobiliza grande potencial de solidariedade.

A partir das narrativas, pudemos confirmar Que a Biodança pode ajudar no enfretamento de barreiras impostas aos idosos, expressas pelo preconceito, isolamento social, falta de respeito aos seus direitos, Quase sempre camuflados pela superproteção ou abandono à solidão, Que se iniciam no ambiente doméstico.

A renovação existencial foi constatada nos discursos, Quando os idosos se descobrem mudados física e mentalmente. O ponto alto da Biodança consistiu na abertura de perspectivas para uma vida melhor, com mais Qualidade; a busca de novidades para o cotidiano, o Que só é possível pelo desenvolvimento do potencial criativo, Que impulsiona as pessoas a recriarem sua existência.

A experiência tem demonstrado ser possível retardar o processo de envelhecer em muitos aspectos, com um trabalho grupal utilizando essa metodologia, uma vez Que estimula a consciência de ter um corpo e de aceitá-lo com as mudanças Que inevitavelmente chegam na velhice.

Temos percebido Que o método da Biodança é eficaz para manter o indivíduo sentindo-se motivado e participativo, evitando seu isolamento social e promovendo a alegria de viver; para promover seu ajustamento e a adaptação ao meio e fortalecer sua identidade, o Que é necessário para o enfrentamento das dificuldades Que surgem com o passar dos anos. Desta forma, a pessoa torna-se plenamente integrada ao mundo e ao mesmo tempo única; aceitando seu corpo com todas as suas funções e imagem corporal modificada pelo envelhecimento; menos reprimida em suas emoções e aberta para a busca do prazer de viver, numa convivência harmoniosa com os outros.

Assim, acreditamos na possibilidade de cura, de resgate da vida, da descoberta do prazer de viver tendo a Biodança como um caminho, entre muitos, Que possibilita esta viagem na redescoberta de si mesmo.

Enfim, o trabalho grupal tem sido visto como excelente meio de ajudar pessoas idosas contra o seu declínio social e promover a saúde delas. No entanto, poucos enfermeiros despertaram para enxergar o potencial Que têm nas mãos.

A atividade grupal, com utilização da Biodança, apresenta-se 
como campo em Que o enfermeiro tem amplo potencial de atuação, uma vez Que essa atividade se constitui numa maneira especial de cuidar, uma forma alternativa de fazer enfermagem - não fazer por eles, mas fazer com eles - levando a pessoa a descobrir-se em sua inteireza, com a saúde do corpo, o equilíbrio emocional necessário para despertar e manter seu valor no mundo.

\section{REFERÊNCIAS}

I. Stevenson IS, Gonçalves LTH, Alvarez, AM. O cuidado e a especialidade de enfermagem geriátrica e gerontológica. Texto Contexto Enferm 1997; 6 (2): 33-42.

2. Goleman D. Inteligência emocional: a teoria revolucionária Que redefine o Que é ser inteligente. 30a ed. Rio de Janeiro: Objetiva; 1995.

3. Toro R. Teoria da Biodança. Fortaleza: ALAB; 1991.

4. Rocha A. A crença no potencial humano. I Biodança I 986; I ( I): 10-8.

5. Moraes GLA. A Biodança contribuindo para diminuição de fatores estressantes no idoso [monografia]. Fortaleza (CE): Departamento de Enfermagem, Universidade Estadual do Ceará; 1996.

6. Alencar BP. O idoso e o trabalho corporal: perspectivas de atuação do enfermeiro [dissertação]. Salvador (BA): Escola de Enfermagem, Universidade Federal da Bahia; 1988.

7. Canuto MLM. Compreendendo o ser hipertenso e os efeitos da biodança. [monografia]. Fortaleza (CE): Departamento de Enfermagem, Universidade Estadual do Ceará; 1997.

8. Silva RM. O conviver com a mastectomia [tese]. Ribeirão Preto (SP): Escola de Enfermagem de Ribeirão Preto, Universidade de São Paulo; 1994.

9. Boykin A, Schoenhofer S. Nursing as caring: a model for transforming practice. New York: National League for Nurses Press; 1993.

10. Bettinelli LA. Solidariedade como cuidado: dimensão e sentido da vida. Florianópolis (SC): UFSC/PEN, 2002.

11. Lüdke M, André MEDA. Pesquisa em educação: abordagens Qualitativas. São Paulo: EPU; 1988.

12. Oliveira RC. O trabalho do antropólogo. São Paulo: Ed. UNESP; 1998.

13. Ricoeur P. Interpretação e ideologias. Rio de Janeiro: Francisco
Alves: 1990.

14. Kleinman A. Pacients and healers in the context of culture. Los Angeles: University of Califórnia Press; 1995.

15. Geertz C. Works and lives: the anthropologist as author. Stanford: Stanford University Press: 1988.

16. Gadamer HG. El estado oculto de la salud. Barcelona: Gedisa; 1996.

17. Eisenberg L. Disease and illness: distinctions between profesional and popular ideas of sickness. Culture Med Psych 1977; 1:923.

18. Good B. Medicine, rationatity and experience: an anthropological perspective. Cambridge: Cambridge University Press; 1996.

19. Fernandes AFC. O cotidiano da mulher com câncer de mama. Fortaleza: UFC; 1997.

20. Helman CG. Cultura Saúde e Doença. Porto Alegre: Artes Médicas; 1994.

21. Moraes MC. Educar na biologia do amor e da solidariedade. Petrópolis: Vozes; 2003.

22. Mariotti H. Autopoiese, Sociedade e Cultura. [citado em: 13 maio 2005]. Disponível em: http:/www.geocities.com/pluriversu

23. Montagu A. Tocar: o significado humano da pele. $7^{\mathrm{a}}$ ed. São Paulo: Summus; 1988.

24. Toro R. Biodança. São Paulo: Escola Paulista de Biodança; 2002.

25. Leite MT, Cappellari VT, Sonego I. Mudou, mudou tudo na minha vida: experiências de idosos em grupos de convivência no município de ljuí/RS. Rev Eletron Enferm 2002; 4(I): 18-25.

26. Góis CWL. Perceber e tecer a vida. In: Cavalcante MRB. Educação Biocêntrica: um movimento de construção dialógica. Fortaleza (CE): Centro de Desenvolvimento Humano; 200I . p. 57-68. 